\title{
Method of obtaining calcium silicate for construction
}

\author{
Evgeny V. Boev* (D), Aigul A. Islamutdinova iD, Elmira K. Aminova (iD \\ Ufa State Petroleum Technological University, Ufa, Russian Federation \\ * Corresponding author: e-mail: 9196011116@mail.ru
}

\begin{abstract}
Introduction. Calcium silicate is one of the well-known building materials. Its structure determines the ability of such nanostructured additives to form a secondary structure - a fractal (volumetrical) network with which cement grains interact. The addition of nanomodifying additives to improve the technology of cement production will reduce the space dimension in which molecules are sorbed on the cement grain, and, accordingly, increase the rate and efficiency of its blocking. Methods and materials. The paper proposes a method for obtaining calcium silicate from soda ash production waste. The sol-gel method for the synthesis of individual nanomodifiers in the silicate form will improve the technology for producing concretes by forming a solid phase state of the modified structure of a cement stone. In the production of soda ash, the land plots (sludge accumulators) are allocated for the collection of production waste (distiller liquid). In this regard, the acute problem is a disposition of industry waste, because the area allocated for sludge accumulators is limited. Results and discussions. The study revealed that the addition of certain components allows us not only to reduce the required firing temperature, but also to affect the nanostructure of the resulting product. The range of values of the content of additives per $5 \mathrm{~g}$ of calcium silicate: $\mathrm{C}-0.2 \div 0.4 ; \mathrm{S}-0.3 \div 0.5 ; \mathrm{ZnO}-0.1 \div 0.3 ; \mathrm{P}_{2} \mathrm{O}_{5}-0.3 \div 0.5$; $\mathrm{NH}_{2} \mathrm{CONH}_{2}-0.3 \div 0.3$. According to the obtained matrix of conditions, 16 samples of substances were prepared. Nanomodification of cement stone leads to its hardening in the early stages of structure formation. Conclusion. The addition of hydroperite to calcium silicate significantly increases the hardness of the final product; when coal, sulfur, zinc oxide and phosphorus pentoxide are added as components, the hardness and structure of the compound changes. Thus, the use of a nanostructured cement additive based on calcium silicate obtained by qualified processing of the main waste that is part of the distiller liquid - calcium oxide, will improve the quality of concrete by improving the technology of cement production.
\end{abstract}

KEYWORDS: distiller liquid, nanomodifier, calcium silicate, nanotechnology, nanostructure, cement stone, concrete.

FOR CITATION: Boev E.V., Islamutdinova A.A., Aminova E.K. Method of obtaining calcium silicate for construction. Nanotechnologies in Construction. 2021; 13(6): 350-357. https://doi.org/10.15828/2075-8545-2021-13-6-350-357.

\section{INTRODUCTION}

$I^{\prime}$ $n$ recent years, in the production of materials based on portland cement, micro- and nanoscale silicon compounds have been used in increasing volumes, along with carbon nanosized particles. Silicate-based particles are cheaper than carbon tubes. Particular attention is drawn to ways of the development of the best possible synthesis methods and the study of the possibilities of practical application of calcium silicates such as wollastonite and xonotlite, which is an intermediate product of the hydrothermal synthesis of wollastonite. This is due to the valuable physicochemical, physicomechanical, thermal properties of xonotlite and wollastonite and a variety of mineral raw materials, which are a potential source for their production. In addition, in Russia, over the years of operation of various industrial enterprises, millions of tons of practically non-recyclable waste based on silicon and calcium have been accumulated. Until the early 90s there was a program of the State Committee for Science and Technology, which provided for research on methods of disposal of such waste. In subsequent years, studies devoted to the "silicate problem" were not carried out.

Currently, there are a large number of methods for producing calcium silicates from various calcium and silicon-containing compounds: melt methods for producing wollastonite, hydrothermal (autoclave) synthesis of calcium hydrosilicates, synthesis by direct solid phase reactions at elevated temperatures. The most promising method for producing calcium silicates is synthesis based on the interaction of the initial components in an aqueous

○ Boev E.V., Islamutdinova A.A., Aminova E.K., 2021 
medium under normal conditions of $20^{\circ} \mathrm{C}$ and a pressure of $1.013-105 \mathrm{~Pa})$.

Fine-grained powders have found wide application as a basis in the study of the processes of obtaining functional materials for various purposes: sorbing agents, solid extractants, compositeceramic and organomineral pigments, hybrid phosphors, pigments, pharmaceutical compounds, etc. [1-5]. In this case, the main task in the selection of raw materials and methods for obtaining hydrosilicates and calcium silicates is to increase the dispersion of powders down to nanometer sizes. Processes for obtaining synthetic calcium silicates from a variety of available raw materials are being investigated in various organizations in our country [6-12]. The first studies in this direction were carried out by Armenian scientists [13]. The use of modern methods for the synthesis of nanostructured calcium silicates, such as the sol-gel process, hydrothermal-microwave synthesis, hydrothermal processes using structuring agents, etc., allows the properties of the target products to be varied over a wide range and thereby ensures their compliance with the requirements for a specific use. Technological processes have been developed for the production of calcium silicates (xonotlite and wollastonite) from technogeneous raw materials (phosphogypsum, silica gel), natural raw materials (diatomite, calcium carbonate), industrial products (lump silicate, calcium chloride), chemical reagents (chloride, nitrate and calcium acetate, sodium silicate, (tetraethoxysilane), established the chemical and technological parameters of the main stages of the processes, developed basic technological schemes, proposed methods of waste management. In case of use of the water-soluble raw materials, processes have been developed for obtaining nanopowders of calcium hydrosilicates using surfactants, in particular, salts of quaternary ammonium bases as structuring additives [14]. It is shown that the obtained precursors with a particle size of $30-70 \mathrm{~nm}$ can be used as sorbents of inorganic salts and organic compounds, as well as for the production of TVEX, organomineral pigments, as fillers in polishing pastes, acrylic paints, etc. The obtained samples of fine-grained nanohydrosilicates of calcium and wollastonite were used to obtain composite ceramic pigments, hybrid luminophors and other materials [15-20].

In the development of the chemical and technological foundations of the processes of joint processing of various types of natural and man-made calcium- and silicon-containing raw materials, we formulated methodological principles and obtained experimental results that allow, on the one hand, to develop rational technological methods for processing specific types of raw materials and to determine the areas of application of the resulting products, and on the other hand, to carry out the choice of raw materials and processing technologies to obtain materials with a given structure and properties [21, 22].
It should be noted that the formation processes, phase and elemental composition, and physicochemical properties of calcium silicates normally synthesized in various systems remain understudied. Therefore, the problem of developing and optimizing the synthesis of calcium hydrosilicates and wollastonite from available raw materials is urgent.

\section{METHODS AND MATERIALS}

It is widely known that at enterprises for the production of soda ash, land plots (sludge collectors) are allocated for the collection of production waste for storing distilled liquid. Similarly, JSC "Soda" in Sterlitamak stores its waste. A territory with an area exceeding 5 million square meters is allocated for sludge collectors. In this regard, there is the acute problem of waste disposing, since the area allotted for sludge collectors is limited. In addition, the open storage of these wastes threatens the surrounding flora and fauna, because it is located $30 \mathrm{me}-$ ters from the banks of the Belaya River. The volume of stored waste is reduced by discharging the settled solution into the Belaya River basin during flood periods, as well as by spontaneous evaporation of water. As a result, "white seas" are formed.

Characteristics of the distilled liquid produced by the production of soda ash of JSC "Soda":

\begin{tabular}{|c|c|}
\hline Component & Content, g/l \\
\hline \multicolumn{2}{|c|}{ Liquid phase } \\
\hline $\mathrm{CaCl}_{2}$ & up to 120 \\
\hline $\mathrm{NaCl}$ & up to 65 \\
\hline $\mathrm{CaSO}_{4}$ & up to 1.3 \\
\hline $\mathrm{Ca}(\mathrm{OH})_{2}+\mathrm{NH}_{4} \mathrm{OH}$ & up to 1.7 \\
\hline \multicolumn{2}{|c|}{ Solid phase } \\
\hline $\mathrm{CaCO}_{3}$ & $4.3-5.2$ \\
\hline $\mathrm{Ca}\left(\mathrm{OH}_{2}\right.$ & $0.5-1.6$ \\
\hline $\mathrm{CaSO}_{4}$ & $0.8-1.8$ \\
\hline
\end{tabular}

Also, the distiller liquid has the following physico-chemical characteristics: $\mathrm{pH}=11,0-11,6$ at $20^{\circ} \mathrm{C}$, $\rho$ about $1,12 \mathrm{~g} / \mathrm{cm}^{3}$ at $20^{\circ} \mathrm{C}, \mathrm{t}_{\text {boiling }}=75-95^{\circ} \mathrm{C}, \mathrm{t}_{\text {freezing }}=$ around $-10^{\circ} \mathrm{C}$.

The final volume occupied by the solid sediment after settling process is up to $18 \%$ of the volume of the original liquid.

Based on the composition of the distiller liquid, it is obvious that the main components of the soda ash production waste are calcium chloride and sodium chloride. Waste storage problem has been partially resolved by JSC "Soda", area No. 2. The company sells the salts extracted from the distilled liquid to municipalities as a means of de-icing on 
highways. But due to the fact that these products are hazardous to the environment (for example, in Moscow and the Moscow region, because of the use of these salts as an anti-icing agent, about 250 thousand trees die annually), the proposed processing method is of limited applicability. In addition, the use of calcium and sodium chlorides on roads and sidewalks leads, firstly, to corrosion of the car body, and secondly, to damage of shoes and wear and tear of car tires. Owing to the above problems, the demand for these salts has recently dropped sharply. In addition, they are used in this area only in the cold season. Despite this use of soda ash production waste, with the current production volume of approximately 1.7 million tons per year, the problem of disposal remains unresolved. 1 ton of soda ash accounts for about 9-10 tons of distilled liquid (or $1: 0.5$ tons in terms of pure calcium chloride and sodium chloride, respectively). As a consequence, the amount of distilled liquid stored in special tanks continues to increase. Due to the fact that the disposal method proposed by the enterprise itself does not allow solving the problem being a threat to the environment, it is required to find a more rational and acceptable solution from an environmental and economic point of view.

Wollastonite is a mineral from the silicate class, a natural calcium silicate with the chemical formula $\mathrm{Ca}_{3}$ $\left(\mathrm{Si}_{3} \mathrm{O}_{9}\right)$, which has a peculiar acicular structure, which is widely used in industry. This mineral is widely used in all industries. Wollastonite is used as a filler additive in plastics, in nonferrous metallurgy, in the tire, asbestoscement and paint and varnish industries, and in the production of ceramics. Tobermorite is a mineral, hydrous calcium silicate $\left[\mathrm{SiO}_{3}\right]_{5} \mathrm{Ca}_{4} \mathrm{H}_{2} \cdot 3 \mathrm{H}_{2} \mathrm{O}$. It is a degradation product of wollastonite. Crystals are acicular, fine-needle like to piliform; form radial-fibrous, stellate and parallelfibrous intergrowths, fine-needle bundles. There are also fibrous-divers and fine-grained aggregates. An artificial analogue of torbermorite is formed in portland cement. Mineral compounds similar to those of the tobermorite group are well known in the cement industry - they are formed by the reaction of cement with water and play an important role in the process of binding cement (concrete). Xonotlite is a product of wollastonite alteration, $\mathrm{Ca}_{6} \mathrm{Si}_{6} \mathrm{O}_{17}(\mathrm{OH})_{2}$. The differential characteristic is in its high hardness.
Amorphous calcium silicate does not contain impurities and water of crystallization and is the main form of calcium silicate obtained synthetically in an aqueous medium.

As the main method for obtaining these compounds, the interaction of calcium chloride from a distilled liquid with sodium silicate from liquid glass is used:

$$
\mathrm{CaCl}_{2}+\mathrm{Na}_{2} \mathrm{SiO}_{3}=\mathrm{CaSiO}_{3}+2 \mathrm{NaCl}
$$

This reaction is carried out with thorough stirring and slowly beating water glass to the distilled liquid. Initially, the distillation liquid is filtered, which precipitates calcium carbonate and aqueous calcium sulfate. These valuable products (chalk, gypsum, asbestos) can be used in the preparation of building materials, for example, dry building mixtures. Then to the resulting filtrate is added in small portions, with stirring, a solution of liquid glass. Due to the high temperature that the distilled liquid has (up to $95^{\circ} \mathrm{C}$ ) after passing through the production cycle and entering for disposal, the above reaction will take place with a high yield. The resulting colloidal solution is concentrated, and calcium metasilicate settles in the form of opalescence at the bottom. With the help of purification, sufficiently pure sodium chloride can be isolated from the resulting filtrate, the concentration of which in the solution will be about $14.5 \%$, which can later be reused in the production of soda ash. The sediment is purified by vacuum filtration and drying. Further, additional components are introduced into it, affecting the structure and quality of the final product. The resulting mixture is sent for firing at an appropriate temperature for 2.5 hours. Depending on the process conditions, we obtain the following valuable products: amorphous calcium silicate, wollastonite, tobermorite and xonotlite of the corresponding structure.

Based on the literature review and patent study, we concluded that the addition of certain components allows us not only to reduce the required firing temperature, but also to affect the structure of the resulting product. Such components are, in particular, coal, microcrystalline sulfur, zinc oxide and phosphorus pentoxide.

Since elemental sulfur and carbon are good reducing agents, we proposed hydroperite - urea with inclusions of

\section{Table 1}

Range of values of the content of additives per $100 \mathrm{~g}$ of calcium silicate

\begin{tabular}{|c|c|c|}
\hline Chemical component & Minimal value & Maximum value \\
\hline $\mathrm{C}$ & 5.26 & 7.37 \\
\hline $\mathrm{S}$ & 5.26 & 10.52 \\
\hline $\mathrm{ZnO}$ & 1.052 & 1.578 \\
\hline $\mathrm{P}_{2} \mathrm{O}_{5}$ & 2.63 & 3.16 \\
\hline
\end{tabular}


hydrogen peroxide molecules as a counterexample of the presented components, the share of the latter being $35 \%$.

Since the mass of calcium silicate after its precipitation and drying is $5 \mathrm{~g}$, the values of the mass of the added components were respectively checked according to the lower and upper limits. So, for coal it is $0.2 \mathrm{~g}$ and 0.4 , for zinc oxide it is $0.1 \mathrm{~g}$ and $0.3 \mathrm{~g}$, for sulfur and phosphorus pentoxide $-0.3 \mathrm{~g}$ and $0.5 \mathrm{~g}$. It was decided to take hydroperite in an amount of $0.3 \mathrm{~g}$ per $10 \mathrm{~g}$ of calcium silicate.

To obtain representative data, the temperatures at which the firing was carried out for 2.5 hours were taken as follows: $800^{\circ} \mathrm{C}, 850^{\circ} \mathrm{C}, 900^{\circ} \mathrm{C}, 950^{\circ} \mathrm{C}$ and $1050^{\circ} \mathrm{C}$.

\section{RESULTS}

According to the obtained matrix of conditions, 16 samples of substances were prepared. To determine their composition, they were subjected to various studies.
As can be seen from the first table, all samples at a given firing temperature $\left(800^{\circ} \mathrm{C}\right)$ are soft. Moreover, their hardness does not depend on the added components. Consequently, the metasilicate probably did not pass into another modification. As it can be seen from the following table, the samples obtained at a temperature of $850^{\circ} \mathrm{C}$ differ from each other in hardness and structure. Consequently, starting from $850^{\circ} \mathrm{C}$, the structure of calcium metasilicate is modified with the formation, presumably, of such minerals as tobermorite, wollastonite, and xonotlite.

The addition of hydroperite to calcium silicate significantly increases the hardness of the final product. When coal, sulfur, zinc oxide and phosphorus pentoxide are added as components, the hardness changes and the structure of the compound decreases - the hardness decreases, and the microcrystals become more amorphous. However, with a further increase in the proportion of ad-

\section{Table 2}

The results of these studies of the physicochemical properties of the obtained samples

\begin{tabular}{|c|c|c|c|c|c|c|c|}
\hline № & $\begin{array}{l}\text { Additional components } \\
\text { gper } 100 \mathrm{~g} \mathrm{CaSiO}_{3}\end{array}$ & $\begin{array}{l}\text { Tempera- } \\
\text { ture, }{ }^{\circ} \mathrm{C}\end{array}$ & Hardness & $\begin{array}{c}\text { Average } \\
\text { diameter of } \\
\text { particles, m }\end{array}$ & $\begin{array}{l}\text { Whiteness, } \\
\text { L }\end{array}$ & $\begin{array}{c}\text { Moisture, } \\
\%\end{array}$ & $\begin{array}{l}\text { Microphotographs } \\
\text { (at } 640 \text { magni- } \\
\text { fication) }\end{array}$ \\
\hline 1 & - & 950 & hard & 10 & 90 & 0.09 & \\
\hline 2 & $\begin{array}{l}\mathrm{C}-0.3 \\
\mathrm{~S}-0.4 \\
\mathrm{ZnO}-0.2 \\
\mathrm{P}_{2} \mathrm{O}_{5}-0.4\end{array}$ & 950 & $\begin{array}{l}\text { medium } \\
\text { hard }\end{array}$ & 10 & 90 & 0.09 & \\
\hline 3 & $\begin{array}{l}\mathrm{C}-0.2 \\
\mathrm{~S}-0.3 \\
\mathrm{ZnO}-0.1 \\
\mathrm{P}_{2} \mathrm{O}_{5}-0.3\end{array}$ & 800 & soft & & & & \\
\hline 4 & $\begin{array}{l}\mathrm{C}-0.4 \\
\mathrm{~S}-0.5 \\
\mathrm{ZnO}-0.3 \\
\mathrm{P}_{2} \mathrm{O}_{5}-0.5\end{array}$ & 800 & soft & & & & \\
\hline
\end{tabular}


APPLICATION OF NANOMATERIALS AND NANOTECHNOLOGIES IN CONSTRUCTION

Table 2 (continued)

\begin{tabular}{|c|c|c|c|c|c|c|c|}
\hline № & $\begin{array}{l}\text { Additional components } \\
\text { gper } 100 \mathrm{~g} \mathrm{CaSiO}_{3}\end{array}$ & $\begin{array}{l}\text { Tempera- } \\
\text { ture, }{ }^{\circ} \mathrm{C}\end{array}$ & Hardness & \begin{tabular}{c|} 
Average \\
diameter of \\
particles, $m$ \\
\end{tabular} & $\begin{array}{c}\text { Whiteness, } \\
\text { L }\end{array}$ & $\begin{array}{c}\text { Moisture, } \\
\%\end{array}$ & $\begin{array}{l}\text { Microphotographs } \\
\text { (at 640 magni- } \\
\text { fication) }\end{array}$ \\
\hline 5 & - & 800 & soft & & & & \\
\hline 6 & $\begin{array}{l}\mathrm{C}-0.2 \\
\mathrm{~S}-0.3 \\
\mathrm{ZnO}-0.1 \\
\mathrm{P}_{2} \mathrm{O}_{5}-0.3\end{array}$ & 800 & soft & & & & \\
\hline 7 & $\begin{array}{l}\mathrm{C}-0.4 \\
\mathrm{~S}-0.5 \\
\mathrm{ZnO}-0.3 \\
\mathrm{P}_{2} \mathrm{O}_{5}-0.5\end{array}$ & 850 & $\begin{array}{l}\text { medium } \\
\text { hard }\end{array}$ & & & & \\
\hline 8 & - & 850 & very hard & & & & \\
\hline 9 & $\begin{array}{l}\mathrm{NH}_{2} \mathrm{CONH}_{2} \cdot \mathrm{H}_{2} \mathrm{O}_{2}- \\
0.3\end{array}$ & 900 & $\begin{array}{l}\text { medium } \\
\text { hard }\end{array}$ & & & & \\
\hline 10 & - & 900 & hard & & & & \\
\hline 11 & $\begin{array}{l}\mathrm{C}-0.2 \\
\mathrm{~S}-0.3 \\
\mathrm{ZnO}-0.1 \\
\mathrm{P}_{2} \mathrm{O}_{5}-0.3\end{array}$ & 900 & soft & & & & \\
\hline
\end{tabular}


Table 2 (continued)

\begin{tabular}{|c|c|c|c|c|c|c|c|}
\hline № & $\begin{array}{c}\text { Additional components } \\
\text { gper } 100 \mathrm{~g} \mathrm{CaSiO}_{3}\end{array}$ & $\begin{array}{l}\text { Tempera- } \\
\text { ture, }{ }^{\circ} \mathbf{C}\end{array}$ & Hardness & $\begin{array}{c}\text { Average } \\
\text { diameter of } \\
\text { particles, } m\end{array}$ & $\begin{array}{c}\text { Whiteness, } \\
\text { L }\end{array}$ & $\begin{array}{c}\text { Moisture, } \\
\%\end{array}$ & $\begin{array}{l}\text { Microphotographs } \\
\text { (at } 640 \text { magni- } \\
\text { fication) }\end{array}$ \\
\hline 12 & $\begin{array}{l}\mathrm{C}-0.4 \\
\mathrm{~S}-0.5 \\
\mathrm{ZnO}-0.3 \\
\mathrm{P}_{2} \mathrm{O}_{5}-0.5\end{array}$ & 900 & hard & & & & \\
\hline 13 & $\begin{array}{l}\mathrm{NH}_{2} \mathrm{CONH}_{2} \cdot \mathrm{H}_{2} \mathrm{O}_{2}- \\
0.3\end{array}$ & 1050 & very hard & & & & \\
\hline 14 & - & 1050 & hard & & & & \\
\hline 15 & $\begin{array}{l}\mathrm{C}-0.2 \\
\mathrm{~S}-0.3 \\
\mathrm{ZnO}-0.1 \\
\mathrm{P}_{2} \mathrm{O}_{5}-0.3\end{array}$ & 1050 & $\begin{array}{l}\text { medium } \\
\text { hard }\end{array}$ & & & & \\
\hline 16 & $\begin{array}{l}\mathrm{C}-0.4 \\
\mathrm{~S}-0.5 \\
\mathrm{ZnO}-0.3 \\
\mathrm{P}_{2} \mathrm{O}_{5}-0.5\end{array}$ & 1050 & hard & & & & \\
\hline
\end{tabular}

ditional components in the mixture, the characteristics of the samples return to their original values.

Researches of the effect of the obtained nano-modified additive on the technological properties of concrete have been carried out. The additive makes it possible to increase the strength of concretes and mortars not by $40 \%$, as suggested by other authors, but by 2 times, but for cellular concrete by 3 to 4 times, and also to reduce the cost of producing nanoadditives by 10 to 15 times in comparison with other modifiers and by 1.5 thousand times compared to nanopowders. The additive is compatible with plasticizers and other modifiers. The introduction of a nanomodifying additive based on calcium silicate makes it possible to eliminate the defectiveness of the concrete structure by filling microcracks and micropores of finegrained concrete with microsilica and the products of its interaction with minerals of cement clinker.

\section{DISCUSSIONS}

The use of elements of different valence and their oxides as nanomodifiers in the production of siliceous materials in various fields of industry, in particular in construction, will make it possible to obtain silicate products 
with high performance characteristics using a simple and affordable technology. All of the above nanomodifying additives allow regulating the technological characteristics of the target product with the desired properties that differ in hardness and their microstructure.

Despite all the research carried out, there are still reasons for our further work in this area. So, for accurate identification and determination of the composition and structure of samples, it would be desirable to photograph them with a magnification of 5000 or more times, as well as instrumentation for determining the hardness on the Mohs scale. In addition, the average particle diameters, whiteness and moisture content are not known for all samples obtained. In this regard, our research in this direction will be continued.

Studies in accordance with GOST Standard 5802-86 showed that water absorption with an increase in the amount of silicate in concrete from 0 to $0.40 \%$ decreases from 22 to $3 \%$, while the pore size decreases. Physicochemical research methods have determined that in the presence of calcium silicate, cement hydration is accelerated, and with the help of differential thermal analysis, it has been established that in the presence of this nanomodifying additive, the amount of chemically bound water increases by $25 \%$. This conclusion is confirmed by the data of calorimetric studies, which showed that the total amount of heat released in 72 hours with calcium silicate is $15 \%$ higher.

\section{CONCLUSION}

Therefore, our studies show that the effect of nanomodification of cement stone is that it hardens faster in the early stages of structure formation and becomes more durable at the end of the hardening process. And this is the basis for the overall reduction of the time of hardening and the rejection of heat treatment of hardening cement. The processing of the obtained experimental data leads to the following conclusion that the introduction of nanomodifying additives in the form of calcium silicate into the cement-water system changes the kinetic parameters of the evolution development and accelerates the hydration of cement by 10 times, which is explained by a decrease in the activation energy of the process by almost 2 times. Obtaining calcium metasilicate and its amorphous derivatives from the main part of the distiller liquid, which is a waste of soda production, can become a promising and alternative way of its utilization. This will make it possible to obtain such valuable products as wollastonite, tobermorite and xonotlite that meet the technical requirements of GOST Standard 4762-7, the world consumption of which is increasing by $5 \%$ annually.

\section{REFERENCES}

1. Akatieva L.V. Synthesis and physico-chemical properties of xonotlite and wollastonite [dissertation]. Moscow:

N.S. Kurnakov Institute of General and Nonorg. Chemistry of the Russian Academy of Sciences; 2003.233 p.

2. Gladun V.D., Kholkin A.I., Akatieva L.V. Prospects for the creation of synthetic wollastonite production in Russia. Chemical technology. 2007; 8(5): 201- 204.

3. Gladun V.D., Akatieva L.V., Andreeva H.H., Kholkin A.I. Obtaining and application of synthetic wollastonite from natural and technogenic raw materials. Chemical Technology. 2004; 9: 2-9.

4. Gladun V.D., Akatieva J1.B., Andreeva N.N., Kholkin A.I. Obtaining xonotlite and prospects for its application. Chemical technology. 2000; 11: 2-9.

5. Schultz M.M. Silicates in nature and human practice. Soros Educational Journal. 1997; 8: 45-51.

6. Bokiy G.B. Crystal chemistry. Moscow: Nauka; 1971.

7. Voitovich V.A., Khryapchenkova I.N., Yavorsky A.A. Nanotechnologies in the production of silicate bricks. Building materials. 2010; 2: 60-61.

8. Mikhailenko N.Yu., Klimenko N.N., Sarkisov P.D. Building materials on a liquid glass binder. Part 1. Liquid glass as a binder in the production of building materials. Technique and technology of silicates. 2012; 19(2): 25-28.

9. Duma J.E. A method for obtaining a water-repellent product, a product and a method for making the surface of a building material waterproof. Patent RF 2190583. 2002-10-10.

10. Beilin D.A., Borisov Yu.M., Figovsky O.L., Surovtsev S. Nanostructuring binder for composite building materials. Patent RF 2408552. 2011-10-01.

11. Ivashchenko Yu.G., Surnin A.A., Meshcheryakov D.V. Composition for the manufacture of construction products. Patent RF 2105738. 1998-02-27.

12. Ivashchenko Yu.G., Fomin R.V. Liquid-glass composition. Patent RF 2235697. 2004-09-10. 
13. Grigoryan G.O., Muradyan A.B., Grigoryan K.G. Wollastonite. Obtaining and application. Armenian Chemical Journal. 1990; 43(5): 296-315.

14. Akulova M.V., Shchepochkina Yu.A. Waterproof silicate coating. Building materials. 1998; 11: 39.

15Akatieva. L.V., Ivanov V.K., Gladun V.D., Kholkin A.I. Obtaining nanoscale powders of calcium hydrosilicates for composite materials. Chemical technology. 2013; 14(4): 199-209.

16. Akatieva L.V., Gladun V.D., Kholkin A.I. A method for producing ceramic alumina-oxide pigment based on nanoscalemesoporous synthetic xonotlite. Patent RF 2493185. 2013-20-09.

17. Akatieva L.V., Kozyukhin S.A. Phosphors based on synthetic calcium silicates. Chemical Technology. 2014; 15(7): 392-400.

18. Gladun V.D., Kholkin A.I., Akatieva L.V. Method for obtaining finely dispersed calcium silicate (variants), finely dispersed calcium silicate (variants), colored composition. Patent RF 2213054. 2003-09-27.

19. Ivashchenko Yu.G., Fomin R.V. Liquid glass composition. Patent RF 2245861. 2005-02-10.

20 Grigoriev P.N., Matveev M.A. Soluble glass (preparation, properties and application). Moscow: State Publishing House of Literature on Building Materials; 1956.

21. Tuktarova M.R., Oparina F.R., Islamutdinova A.A. Disposal of distiller liquid to produce wollastonite. In: The Proceedings of the 63rd Scientific and Technical Conference of Students, Postgraduates and Young Scientists. Ufa: UGNTU; 2012. p. 372.

22. Ivanov A. N., Karimov, O. H., Islamutdinov A. A. Recycling soda production with the use of microwave radiation. Bulletin of the young scientist UGNTU. 2015; 1(1): 38-41.

\section{INFORMATION ABOUTTHE AUTHORS}

Evgeniy V. Boev - Cand. Sci. (Eng.), Associate Professor, Head of the Department of General Chemical Technology, Sterlitamak Branch of USPTU, Republic of Bashkortostan, Russia, 9196011116@mail.ru, https://orcid.org/0000-0001-9255-6142

Aigul A. Islamutdinova - Cand. Sci. (Eng.), Associate Professor, Associate Professor of the Department "General Chemical Technology", Sterlitamak Branch of USPTU, Sterlitamak, Russia, aygul_ru@mail.ru, https://orcid.org/0000-0003-3104-2097

Elmira K. Aminova - Cand. Sci. (Chem.), Associate Professor, Associate Professor of the Department of General Chemical Technology, Sterlitamak Branch of USPTU, Republic of Bashkortostan, Russia, k.elmira.k@yandex.ru, https://orcid.org/0000-0002-3105-3477

\section{CONTRIBUTION OF THE AUTHORS}

The authors contributed equally to this article.

\section{The authors declare no conflicts of interests.}

The article was submitted 07.10.2021; approved after reviewing 02.11.2021; accepted for publication 12.11.2021. 